OPEN ACCESS

Edited by:

Marcel Willem Bekkenk,

Academic Medical

Center, Netherlands

Reviewed by:

Andreas Recke,

University of Lübeck, Germany

Zrinka Bukvic Mokos,

University Hospital Center

Zagreb, Croatia

${ }^{*}$ Correspondence:

Manuel Pedro Pereira manuelpedro.pereira@ukmuenster.de

Specialty section: This article was submitted to Dermatology,

a section of the journal

Frontiers in Medicine

Received: 14 December 2020 Accepted: 03 February 2021

Published: 24 February 2021

Citation:

Pereira MP, Wiegmann $\mathrm{H}$ Agelopoulos K and Ständer S (2021) Neuropathic Itch: Routes to Clinical Diagnosis. Front. Med. 8:641746. doi: $10.3389 /$ fmed.2021.641746

\section{Neuropathic Itch: Routes to Clinical Diagnosis}

\author{
Manuel Pedro Pereira*, Henning Wiegmann, Konstantin Agelopoulos and Sonja Ständer \\ Department of Dermatology and Center for Chronic Pruritus, University Hospital Münster, Münster, Germany
}

Neuropathic itch occurs due to damage of neurons of the peripheral or central nervous system. Several entities, including metabolic, neurodegenerative, orthopedic, infectious, autoimmune, malignant, and iatrogenic conditions, may affect the somatosensory system and induce neuropathic itch. Due to the complex nature of neuropathic itch, particularly concerning its clinical presentation and possible etiological factors, diagnostic work-up of this condition is challenging. A detailed medical history, especially in regard to the itch, and a comprehensive physical examination are relevant to detect characteristic signs and symptoms of neuropathic itch and to rule out other possible causes for chronic itch. Complementary diagnostic exams, especially laboratory tests, determination of the intraepidermal nerve fiber density via a skin biopsy and radiological examinations may be indicated to confirm the diagnosis of neuropathic itch and to identify underlying etiological factors. Functional assessments such as quantitative sensory testing, nerve conduction studies, evoked potentials, or microneurography may be considered in particular cases. This review article provides a comprehensive overview of the diagnostic work-up recommended for patients with neuropathic itch.

Keywords: neuropathic itch, chronic itch, dysesthesia, pain, small-fiber neuropathy, diagnostic work-up, intraepidermal nerve fiber density, magnet resonance imaging

\section{INTRODUCTION}

The International Forum for the Study of Itch (IFSI) defines neuropathic itch as itch occurring due to an injury of neurons of the peripheral or central nervous system (1). It is estimated that $8 \%$ of chronic itch cases have a neuropathic origin (2). However, epidemiological studies investigating the prevalence and incidence of neuropathic itch are still missing.

Damage at any site of the somatosensory system, including peripherally nerve fibers, nerve plexuses and ganglia, and centrally the spinal cord, brainstem, thalamus or cortex, may lead to neuropathic itch (3).

Several conditions affecting the peripheral nervous system are associated with neuropathic itch (Table 1). In small-fiber neuropathy (SFN), which results from injured C- and A $\delta$ fibers (4), itch and pain may occur localized (mostly distally at the feet) or generalized. It may result from a myriad of conditions such as metabolic (e.g., diabetes), infectious, autoimmune and genetic diseases. Also drugs (e.g., chemotherapy) and alcohol may induce SFN $(5,6)$. Scars and burninjuries are often associated with itch, likely due to damage of cutaneous nerves $(7,8)$. Postherpetic neuralgia is a frequent cause of neuropathic itch at the site of the affected peripheral nerve (9). Compression or irritation of different neural structures may induce localized neuropathic itch along the corresponding dermatome, as is the case in brachioradial pruritus (radiculopathy at $\mathrm{C} 3-\mathrm{C} 6$ ), notalgia paresthetica (dorsal rami of posterior nerves at $\mathrm{T} 2-\mathrm{T} 6$ ), cheiralgia paresthetica 
TABLE 1 | Neuropathic pruritic conditions.

\begin{tabular}{|c|c|c|c|}
\hline Disease & Etiology & Clinical features & Main work-up \\
\hline \multicolumn{4}{|l|}{ Peripheral nervous system } \\
\hline Small fiber neuropathy & $\begin{array}{l}\text { Metabolic, drug-induced, infectious, or } \\
\text { genetic origin }\end{array}$ & $\begin{array}{l}\text { Itch starts usually distally and may } \\
\text { generalize }\end{array}$ & IENFD, QST \\
\hline Scars and burns & latrogenic or traumatic & Itch on lesional tissue & Clinical diagnosis \\
\hline Radiculopathies & $\begin{array}{l}\text { Compression of a peripheral nerve by } \\
\text { degenerative alterations or } \\
\text { space-occupying lesions }\end{array}$ & $\begin{array}{l}\text { Itch and dysesthesias at the affected } \\
\text { dermatome }\end{array}$ & MRI or CT scan, IENFD \\
\hline Postherpetic neuralgia & $\begin{array}{l}\text { Damage of peripheral nerve by the varicella } \\
\text { zoster virus }\end{array}$ & $\begin{array}{l}\text { Itch and dysesthesias at the affected } \\
\text { dermatome }\end{array}$ & Clinical diagnosis \\
\hline Trigeminal trophic syndrome & $\begin{array}{l}\text { Injury of the sensory fibers of the trigeminal } \\
\text { nerve }\end{array}$ & $\begin{array}{l}\text { Unilateral dysesthesia and } \\
\text { hypoesthesia of the central face. } \\
\text { Self-induced ulceration of the nasal } \\
\text { ala, cheek, and upper lip }\end{array}$ & Clinical diagnosis, MRI \\
\hline \multicolumn{4}{|l|}{ Central nervous system } \\
\hline Space occupying lesions & $\begin{array}{l}\text { Tumors, abscesses, vascular lesions, } \\
\text { syringomyelia }\end{array}$ & $\begin{array}{l}\text { Clinical features according to affected } \\
\text { neural structures }\end{array}$ & Neuroimaging (MRI/CT scan) \\
\hline Stroke & Ischemic or hemorrhagic & Generalized or unilateral itch & Neuroimaging (CT scan) \\
\hline Multiple sclerosis & Demyelinating disease & $\begin{array}{l}\text { Generalized itch or localized at the } \\
\text { head and upper back }\end{array}$ & $\begin{array}{l}\text { MRI, analysis of cerebrospinal fluid } \\
\text { (IgG oligoclonal bands), evoked } \\
\text { potentials }\end{array}$ \\
\hline Neuromyelitis optica & Demyelinating disease & Depending on injured spinal level & $\begin{array}{l}\text { MRI, autoantibodies against } \\
\text { aquaporin } 4\end{array}$ \\
\hline Infectious diseases & Meningitis, encephalitis, prion disease & $\begin{array}{l}\text { Depending on damaged neural } \\
\text { structures }\end{array}$ & $\begin{array}{l}\text { Neuroimaging (MRI/CT scan), analysis } \\
\text { of cerebrospinal fluid, blood tests }\end{array}$ \\
\hline $\begin{array}{l}\text { Traumatic brain or spinal } \\
\text { cord lesions }\end{array}$ & Accidents or iatrogenic lesions & $\begin{array}{l}\text { Depending on damaged neural } \\
\text { structures }\end{array}$ & Neuroimaging (MRI/CT scan) \\
\hline
\end{tabular}

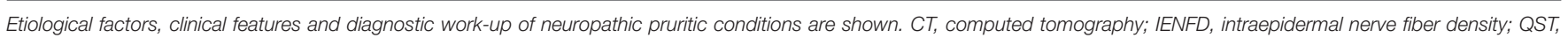
quantitative sensory testing; MRI, magnet resonance imaging.

(radial nerve), meralgia paresthetica (lateral femoral cutaneous nerve), and gonyalgia paresthetica (infrapatellar branch of the saphenous nerve) $(2,10-13)$. Genitoanal itch, a common pruritic condition, can also have a neuropathic origin, due to a lumbosacral radiculopathy. Injury of the trigeminal nerve may cause facial itch leading often to manipulation of the skin with ulceration, a condition termed trigeminal trophic syndrome (14).

At central level, space-occupying lesions such as abscesses, cysts, tumors, vascular malformations or syringomyelia may originate neuropathic itch $(15,16)$. Also neural damage induced by trauma or meningitis has been associated with the occurrence of itch, while unilateral itch has been reported after a stroke (17, 18). Additionally, itch has been reported in neuroinflammatory conditions as for instance multiple sclerosis or neuromyelitis optica $(19,20)$.

Neuropathic itch should be differentiated from other etiologies possibly underlying itch. Table 2 provides an overview of potential etiologies of chronic itch as defined by the IFSI, including clinical examples and distinctive clinical features.

Owing to the multidimensional nature of neuropathic itch, particularly regarding its clinical presentation and possible

Abbreviations: CT, computed tomography; DN4, doleur neuropathique; IENFD, intraepidermal nerve fiber density; IFSI, International Forum for the Study of Itch; QST, quantitative sensory testing; MRI, magnet resonance imaging; NP5, Neuropathic Pruritus 5; SFN, small-fiber neuropathy. underlying causes, substantial diagnostic efforts are necessary in the management of these patients. This review article focuses on the diagnostic work-up of patients with neuropathic itch, including the medical history and physical examination (Table 3), use of standardized questionnaires, laboratory tests, skin biopsies for the assessment of neurocutaneous alterations, radiological examinations, and functional tests (Table 4).

\section{MEDICAL HISTORY}

A detailed medical history is essential for the diagnosis of neuropathic itch and to exclude other possible etiologies for chronic pruritus. The itch characteristics should be asked in detail. The beginning of the pruritus and possible associated relevant events (e.g., herpes zoster prior to postherpetic neuralgia, or treatment with chemotherapy resulting in SFN) may give important clues of its etiology. Additionally, the appearance of the skin at the onset of the disease should be asked. Neuropathic itch starts on normal appearing skin, as no primary skin condition is present, but excoriations or chronic scratch lesions (e.g., chronic nodular prurigo or lichen simplex) may develop at a later stage due to ongoing scratching behavior (Figure 1) (21).

Also the localization of itch at the beginning and during the course of the disease should be addressed. The affected site of 
TABLE 2 | Etiological classification of itch.

\begin{tabular}{|c|c|c|c|c|}
\hline \multicolumn{2}{|l|}{ Etiology } & \multicolumn{2}{|l|}{ Clinical examples } & Clinical features \\
\hline \multicolumn{2}{|l|}{ Dermatological } & \multicolumn{2}{|c|}{$\begin{array}{l}\text { Atopic dermatitis, cutaneous T-cell } \\
\text { Iymphoma, psoriasis, urticaria }\end{array}$} & Primary skin alterations (e.g., eczema) can be found upon inspection \\
\hline \multicolumn{2}{|l|}{ Systemic } & \multicolumn{2}{|c|}{$\begin{array}{l}\text { Cholestasis, diabetes, drug-induced, } \\
\text { myeloproliferative disorders, renal } \\
\text { insufficiency, solid tumors }\end{array}$} & $\begin{array}{l}\text { Temporal correlation between onset of systemic disease and begin of itch may hint toward a } \\
\text { systemic origin of itch } \\
\text { Onset of itch at the trunk is typical for diabetes, while begin of itch at the palms and soles } \\
\text { suggests a liver disease as an underlying cause }\end{array}$ \\
\hline \multicolumn{2}{|l|}{ Neuropathic } & \multicolumn{2}{|c|}{$\begin{array}{l}\text { Brachioradial pruritus, notalgia } \\
\text { paresthetica, postherpetic neuralgia, } \\
\text { small-fiber neuropathy }\end{array}$} & $\begin{array}{l}\text { Itch usually starts localized according to the affected nerves. Symptomatic alleviation with } \\
\text { application of cold or ice }\end{array}$ \\
\hline \multicolumn{2}{|c|}{ Psychosomatic/psychiatric } & \multicolumn{2}{|c|}{$\begin{array}{l}\text { Delusional parasitosis, somatoform } \\
\text { pruritus }\end{array}$} & Onset of itch may occur after a significant life event (e.g., death of the partner, job loss) \\
\hline \multicolumn{2}{|l|}{ Mixed } & \multicolumn{2}{|c|}{ If more than one etiology is found } & Occurs more frequently in older or multimorbid patients \\
\hline \multicolumn{2}{|l|}{ Unknown } & \multicolumn{2}{|c|}{$\begin{array}{l}\text { If no underlying etiology is found after } \\
\text { diagnostic work-up }\end{array}$} & Diagnostic work-up should be repeated yearly if the cause for chronic itch remains unknown \\
\hline \multicolumn{5}{|c|}{ Adapted from Ständer et al. (1). } \\
\hline & \multicolumn{2}{|c|}{ Parameter } & \multicolumn{2}{|c|}{ Comment } \\
\hline \multicolumn{5}{|l|}{ Medical history } \\
\hline \multirow{7}{*}{$\begin{array}{l}\text { Itch specific } \\
\text { history }\end{array}$} & \multicolumn{2}{|l|}{ Intensity } & \multicolumn{2}{|c|}{ Itch intensity informs about the disease severity and should be monitored during the course of the disease } \\
\hline & \multicolumn{2}{|c|}{ Sensory symptoms } & \multicolumn{2}{|c|}{ Dysesthesias such as stinging, tingling or sensation like electroshocks are typical for neuropathic itch } \\
\hline & \multicolumn{2}{|c|}{ Daily pattern } & \multicolumn{2}{|c|}{ Itch usually occurs in attacks in neuropathic itch } \\
\hline & \multicolumn{2}{|c|}{ Localization at onset } & \multicolumn{2}{|c|}{ Localization of the itch at onset gives important hints regarding the affected site of the somatosensory system } \\
\hline & \multicolumn{2}{|c|}{ Localization in the course of disease } & \multicolumn{2}{|c|}{ Generalization of itch beyond the initial localization at onset may occur, suggesting neuronal sensitization } \\
\hline & \multicolumn{2}{|c|}{ Alleviating factors } & \multicolumn{2}{|c|}{$\begin{array}{l}\text { Alleviation of sensory symptoms with application of cool-packs or cold water is characteristic for neuropathic } \\
\text { itch (ice-pack sign) }\end{array}$} \\
\hline & \multicolumn{2}{|c|}{ Performed therapies } & \multicolumn{2}{|c|}{$\begin{array}{l}\text { Neuropathic itch is expected to improve with gabapentinoids or opioid modulators, while antihistamines are } \\
\text { usually ineffective }\end{array}$} \\
\hline \multirow[t]{2}{*}{$\begin{array}{l}\text { General medical } \\
\text { history }\end{array}$} & Comorbi & idities & $\begin{array}{l}\text { Assessr } \\
\text { leading } \\
\text { options }\end{array}$ & $\begin{array}{l}\text { f comorbidities including atopic conditions is important to rule out non-neuropathic conditions } \\
\text { onic pruritus. Additionally, systemic conditions (e.g., renal insufficiency) may limit therapeutic }\end{array}$ \\
\hline & Co-med & ication & Co-mec & should be assessed to exclude possible drug interactions when planning an antipruritic therapy \\
\hline Physical examin & ation & & & \\
\hline $\begin{array}{l}\text { Dermatological } \\
\text { examination }\end{array}$ & Dermato & ses & $\begin{array}{l}\text { Primary } \\
\text { eventua }\end{array}$ & $\begin{array}{l}\text { onditions as a possible cause for chronic itch should be ruled out by clinical examination (and } \\
\text { skin biopsies). Importantly, dermatoses should be differentiated from secondary scratch lesions }\end{array}$ \\
\hline & Scratch & lesions & $\begin{array}{l}\text { The dist } \\
\text { somato } \\
\text { disease }\end{array}$ & $\begin{array}{l}\text { n of scratch lesions (along with the sensory symptoms) may inform on the affected site of the } \\
\text { y system. Additionally the amount of scratch lesions may serve as an indirect indicator of } \\
\text { ty }\end{array}$ \\
\hline $\begin{array}{l}\text { Neurological } \\
\text { examination }\end{array}$ & Alloknes & is, Hyperknesis & $\begin{array}{l}\text { Pruritic } \\
\text { stimulus }\end{array}$ & $\begin{array}{l}\text { Ise to a non-pruritic stimulus (e.g., cotton swab) and augmented pruritic response to a pruritic } \\
\text { skin challenge with cowhage) suggest neuronal sensitization }\end{array}$ \\
\hline & Mapping & of dysesthesias & $\begin{array}{l}\text { Mappin } \\
\text { syndron }\end{array}$ & $\begin{array}{l}\text { of dysesthesia (and alloknesis/hyperknesis) is helpful in localized pruritic neuropathic } \\
\text { it may give hints on the affected neural structure }\end{array}$ \\
\hline
\end{tabular}

the somatosensory system is of paramount importance for the localization of itch. However, generalization of itch may occur after initial localized begin (22).

Pruritus intensity, accompanying sensory symptoms, fluctuation of the itch during the day and alleviating factors should be assessed. Typical for neuropathic itch is the presence of additional dysesthesias such as stinging and tingling, occurrence of itch in attacks and alleviation of the symptoms after application of cool-packs or cold water (Figure 1) $(5,23)$.

Moreover, information on previous antipruritic therapies and their effect and tolerance may help guiding the decision on further therapeutic proceedings $(24,25)$.

In addition to the itch specific history, the general medical history, especially regarding comorbidities and co-medication are important to rule other possible factors contributing to the 
TABLE 4 | Complementary diagnostic procedures in neuropathic itch.

\begin{tabular}{|c|c|}
\hline Diagnostic procedure & Comment \\
\hline Laboratory tests & $\begin{array}{l}\text { - Exclusion of systemic disease as underlying cause } \\
\text { - Ex chronic pruritus } \\
\text { - Exploratory work-up to investigate possible } \\
\text { - Conditions inducing small-fiber neuropathy } \\
\text { oligoclonal bands in multiple sclerosis) } \\
\text { - Genetic work-up if hereditary conditions (e.g., } \\
\text { genetic small-fiber neuropathy and } \\
\text { channelopathy) is suspected }\end{array}$ \\
\hline Skin biopsy & $\begin{array}{l}\text { - Determination of the intraepidermal nerve fiber } \\
\text { density to detect alterations of the cutaneous } \\
\text { neuroanatomical architecture } \\
\text { - Histology and/or direct immunofluorescence to } \\
\text { rule out a primary skin condition }\end{array}$ \\
\hline Radiological examinations & $\begin{array}{l}\text { - Magnet resonance imaging (MRI)/computed } \\
\text { tomography (CT) to identify space-occupying } \\
\text { lesions affecting the central or peripheral nervous } \\
\text { system } \\
\text { - MRI (alternatively CT) to detect spinal disorders } \\
\text { (e.g., degenerative alterations of the vertebral } \\
\text { column, disc prolapse or herniation, compression } \\
\text { of nerve roots or spinal nerves, neuroforaminal } \\
\text { stenosis) in patients with pruritic compression } \\
\text { syndromes } \\
\text { - Diagnosis of neurological conditions potentially } \\
\text { inducing itch (e.g., stroke, meningitis, } \\
\text { multiple sclerosis) }\end{array}$ \\
\hline Functional assessments & $\begin{array}{l}\text { - Quantitative sensory testing to assess gain or loss } \\
\text { of function of different populations of peripheral } \\
\text { nerve fibers, including C and A } \delta \text {-fibers, and to } \\
\text { detect possible signs of neuronal sensitization } \\
\text { - Nerve conduction studies and electromyography } \\
\text { to investigate impairment of large sensory (and } \\
\text { motor) nerves } \\
\text { - Microneurography and evoked potentials allow } \\
\text { the assessment of selective nerve fibers, but are } \\
\text { mostly used in research }\end{array}$ \\
\hline
\end{tabular}

development of pruritus and to inform on eventual limitations of therapeutic options due to drug interactions or systemic conditions as for instance impairment of renal or liver function $(24,25)$.

\section{PHYSICAL EXAMINATION}

A comprehensive dermatological examination of the entire skin including mucosae is advised $(24,25)$. In neuropathic itch, no primary skin diseases are expected to be found. These should be differentiated from secondary lesions resulting from scratching such as excoriations or lichenification $(24,25)$. The distribution pattern of possible scratch marks and/or of the reported symptoms in localized pruritic conditions is essential for the correct diagnosis of the neuropathy. For instance, SFN manifests initially distally at the feet and advance proximally with the course of the disease, whereas neuropathic itch due to postherpetic neuralgia occurs at the affected dermatome.
Brachioradial pruritus affects the outer aspects of the arms, while in notalgia paresthetica a circumscribed hyperpigmented area due to rubbing, mostly between the scapulae at the back, is characteristic (26). Unilateral itch should raise suspicion of a past stroke (17).

Alloknesis, i.e., induction of itch after application of a nonpruritic stimulus, and hyperknesis, i.e., augmented itch response to a pruritic stimulus, may occur in neuropathic itch (27) and should be assessed in these patients. A typical example for alloknesis often reported by patients is an intense itch perception after light touch of the skin in an affected site. These phenomena argue for neuronal sensitization processes, which contribute to the chronicity of the itch (28).

\section{STANDARDIZED QUESTIONNAIRES}

Standardized questionnaires, as for instance the doleur neuropathique (DN4) (29), PainDetect (30), or the Brief Pain Inventory (31), have been successfully developed to screen for neuropathic pain (32). For neuropathic itch no such tools were available until recently, when a score to differentiate neuropathic from non-neuropathic itch based on patient reported outcomes was proposed. Independent factors for neuropathic itch were the presence of twinges, absence of burning, worsening of the itch with activity, no worsening with stress and relief of itch with cold temperature. As a result, the Neuropathic Pruritus 5 (NP5) score was suggested based on the 5 independent factors for neuropathic itch. The presence of two out of five criteria yield a sensitivity of $76 \%$ and a specificity of $77 \%$ in discriminating neuropathic from non-neuropathic itch (33). For SFN a patient oriented survey including a question on itchy skin is in development (34).

\section{SKIN BIOPSY: INTRAEPIDERMAL NERVE FIBER DENSITY}

Neurocutaneous morphological alterations are observed in neuropathic pruritic conditions. The determination of the intraepidermal nerve fiber density (IENFD) is the gold standard for the diagnosis of a SFN (5). Additionally, a reduction of the IENFD is also observed in neuropathic compression syndromes as for instance brachioradial pruritus (35). Thus, the examination of the epidermal neural architecture may provide important hints for the diagnosis of a neuropathic pruritic condition. Clinically, the magnitude of the decrease in IENFD seems to influence the perception of dysesthesias (5).

In order to determine the IENFD when neuropathic itch is suspected, a skin sample is obtained via a punch biopsy from non-lesional pruritic skin. Importantly, scratch lesions, scars or other skin conditions (e.g., eczema, skin infections) should be avoided when choosing the biopsy site, since such alterations may lead to false pathological findings. After staining of the skin sample with an axonal marker (e.g., protein gene 


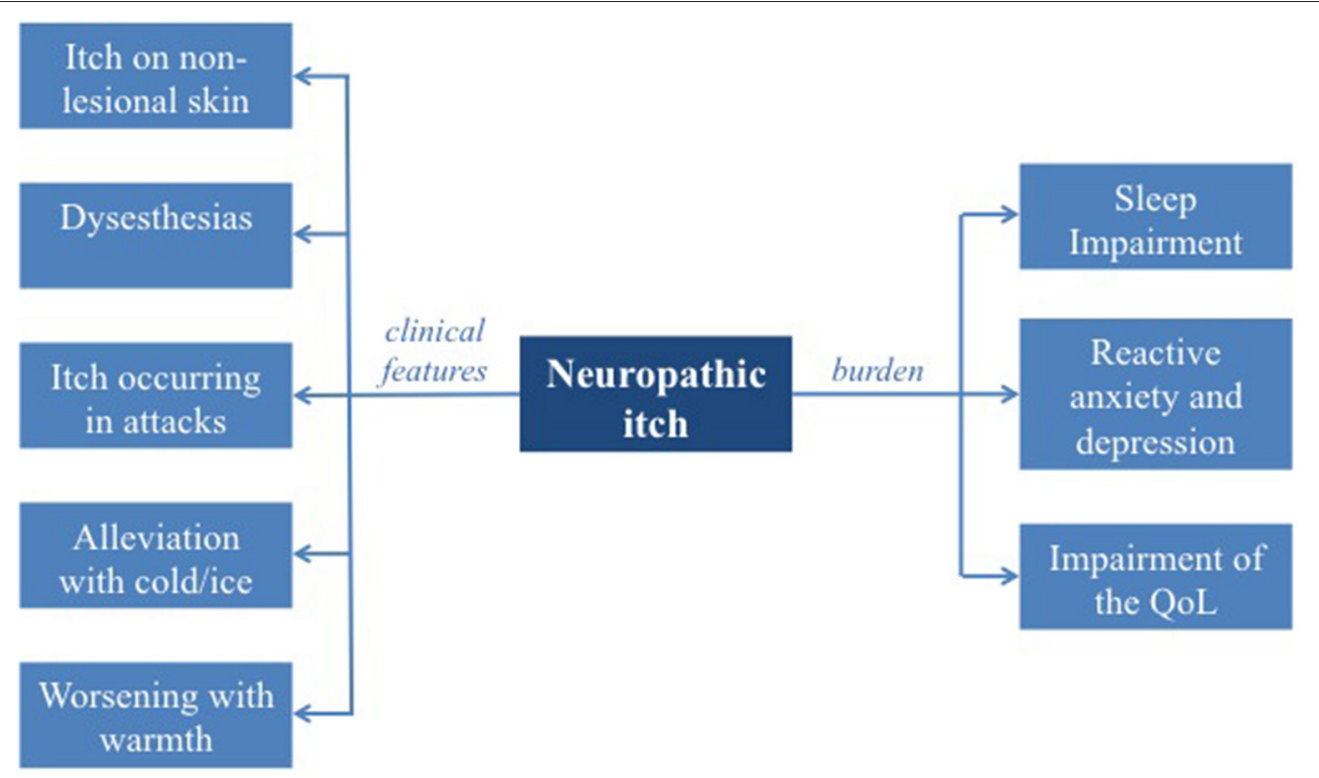

FIGURE 1 | Neuropathic itch: clinical features and burden.

product 9.5), nerve fibers crossing the basal membrane from the dermis into the epidermis are counted and divided by the length of the dermoepidermal junction. Fragments of nerve fibers in the epidermis and branching are not considered for the IENFD (36). Reference values are currently only available for the innervation site of the sural nerve (37). Therefore, this area (lateral lower leg) should be chosen for the biopsy, if patients report dysesthesias there. If another body site is affected, a skin sample from a non-affected symmetrical region should be obtained for comparison.

\section{LABORATORY TESTS}

Laboratory tests are indicated to rule out non-neuropathic conditions potentially inducing chronic itch, as for instance renal retention parameters to exclude renal insufficiency, cholestasis parameters or complete blood count to screen for hematooncological diseases $(24,25)$. Moreover, disease specific tests should be performed in selected patients with suspicion of a neurologic condition (e.g., analysis of cerebrospinal fluid including histology if a brain tumor is suspected, or oligoclonal bands for the diagnosis of multiple sclerosis) (24).

Additionally, after a SFN is diagnosed laboratory investigations should be performed in order to identify possible causes. The assessment of glycosylated hemoglobin to rule out diabetes, vitamin B12 and folate serum levels, HIV and hepatitis B and C serology, TSH, and antinuclear antibodies constitute the most relevant assessments. Additionally, genetic tests may be considered for young patients with SFN of unclear origin to exclude a hereditary condition. However, in spite of a comprehensive work-up, the etiology of SFN remains unknown in a substantial number of cases (38).

\section{RADIOLOGICAL EXAMINATIONS}

Diagnostic imaging, especially magnet resonance imaging (MRI) and computed tomography (CT), is helpful to detect spaceoccupying lesions such as tumors, abscesses, vascular or inflammatory lesions and their anatomical relationship to peripheral or central neural structures. Medical imaging plays also a relevant role in the diagnosis of neurological conditions as e.g., stroke, meningitis or degenerative neuroinflammatory diseases, which potentially induce neuropathic itch.

MRI [alternatively CT, high-resolution sonography or MR neurography (39)] is oftentimes used in the diagnostic workup of pruritic neuropathic compression syndromes to identify underlying pathologies such as compression of nerve roots or of the spinal cord, disc prolapse or herniation, degenerative vertebral alterations, osteophytes or neuroforaminal stenosis (10, 11,26). While in brachioradial pruritus there is a clear correlation between MRI findings and the localization of dysesthesias, such a relationship is not so clear for notalgia paresthetica (40).

\section{FUNCTIONAL ASSESSMENTS}

Morphological investigations of neuroanatomical alterations may be complemented with functional assessments in patients with neuropathic itch. The small unmyelinated C-fibers and thinly myelinated $\mathrm{A} \delta$-fibers are of particular interest, as they transmit itch $(41,42)$. In quantitative sensory testing (QST), a validated test battery using thermal and mechanical standardized stimuli, detection and pain thresholds as well as response to suprathreshold stimuli are measured, allowing to infer a possible gain or loss of function of different nerve fiber populations (43-45). Additionally, QST informs about signs of neuronal sensitization, for instance by assessing mechanical allodynia 
and wind-up ratio (46). Although this non-invasive method provides a comprehensive neurophysiological profiling of sensory neuropathies, it is time-consuming, requires specialized personnel and the collaboration of the patient.

Large myelinated sensory fibers are not involved in itch transmission. Nevertheless, SFN may occur as part of a polyneuropathy with involvement of large fibers. Therefore, in patients with neuropathic pruritus due to a SFN, referral to a neurologist for nerve conduction studies or electromyography should be considered (3). Additionally patients with pruritic compression diseases may show pathological nerve conduction studies, as has been reported in brachioradial pruritus (47) and anogenital neuropathic itch (48).

Assessment of evoked potentials and microneurography constitute additional methods, in which functional impairment of selective nerve fibers are investigated $(49,50)$. These diagnostic procedures are mostly performed in research studies, but may be considered in selected clinical cases.

\section{DISCUSSION}

The diagnosis of neuropathic itch is challenging and may be overlooked in routine care. Neuropathic itch should be suspected in patients with chronic itch on normal appearing skin without a relevant systemic condition causing itch. A detailed medical history, especially in relation to the sensory symptoms, can further suggest the presence of a neuropathic origin. Typical is the presence of additional dysesthesias such as stinging and tingling, the occurrence of symptoms in attacks rather than continuously and alleviation with coolpacks or cold temperature. These clinical symptoms have been proposed as diagnostic criteria for pruritic SFN (5). However, these symptoms are not exclusive of neuropathic pruritic conditions. For instance, sensory symptoms other than itch such as crawling, tickling, and stinging have been reported in atopic dermatitis (51), while pain is perceived by the majority of patients with atopic dermatitis and psoriasis (52).

The localization of the dysesthesias, especially when distributed along a dermatome (e.g., in post-herpetic neuralgia or brachioradial pruritus) or in a stocking-and-glove distribution (e.g., in SFN), may yield further clues to the diagnosis of neuropathic itch and to the localization of the pathology within the somatosensory system (26).

Moreover, alloknesis, which can be easily tested by stimulating the affected skin area with a cotton wool or a brush, should be included in the evaluation of patients, as this phenomenon is characteristic of neuropathic itch, especially when neuronal sensitization has ensued (28).

\section{REFERENCES}

1. Ständer S, Weisshaar E, Mettang T, Szepietowski JC, Carstens E, Ikoma A, et al. Clinical classification of itch: a position paper of the International Forum for the Study of Itch. Acta Derm Venereol. (2007) 87:291-4. doi: 10.2340/00015555-0305
Complementary exams are indicated to confirm a suspicious case of neuropathic itch. The determination of the IENFD, which is frequently reduced in neuropathic itch, is the gold-standard test to diagnose involvement of small-fibers. The biopsy needs to be performed at a pruritic non-lesional site, since the IENFD is also reduced in chronic scratch lesions (53) and in dermatoses (54-56), suggesting a neuropathic component of inflammatory pruritic conditions. However, while in chronic scratch lesions the IENFD normalizes with healing of the lesions, in neuropathic syndromes such as pruritic SFN and brachioradial pruritus the IENFD seems to be independent of the amount of scratch lesions present, arguing for an endogenous neuropathic mechanism leading to the rarefication of intraepidermal fibers $(5,35)$. A reduced IENFD is found not only in SFN, but also in extracutaneous neuropathic conditions such as brachioradial pruritus, likely due to anterograde transmission of neuromodulating factors leading to cutaneous neuroanatomical changes $(57,58)$.

Radiological exams, especially MRI, are useful when a neuropathic compression syndrome is suspected to identify orthopedic pathologies compromising neural structures. It should however be taken into account that in some cases anatomical abnormalities leading to neuropathic itch may be difficult to identify with medical imaging, as is the case in notalgia paresthetica (40).

In the management of patients with suspected neuropathic itch, diagnostic efforts focus on confirming the diagnosis and identifying the underlying pathological processes at the somatosensory system. With the advance of the understanding of the neurobiological mechanisms leading to neuropathic itch and their association with clinical signs and symptoms, a mechanism driven diagnostic work-up may be possible in the future, allowing the use of target specific drugs, which hopefully will result in a better care.

\section{AUTHOR CONTRIBUTIONS}

MP planned the manuscript, performed the literature search, wrote the manuscript, and approved the final version of the manuscript. HW performed the literature search, wrote the manuscript, and approved the final version of the manuscript. KA wrote the manuscript and approved the final version of the manuscript. SS planned the manuscript, wrote the manuscript, and approved the final version of the manuscript. All authors contributed to the article and approved the submitted version.

\section{FUNDING}

This work was supported by a grant from the German Research Foundation (DFG) to SS (STA1159/4-1) and to KA (AG271/1-1).

2. Stumpf A, Ständer S. Neuropathic itch: diagnosis and management. Dermatol Ther. (2013) 26:104-9. doi: 10.1111/dth. 12028

3. Misery L, Brenaut E, Le Garrec R, Abasq C, Genestet S, Marcorelles P, et al. Neuropathic pruritus. Nat Rev Neurol. (2014) 10:408-16. doi: $10.1038 /$ nrneurol.2014.99 
4. Oaklander AL. Neuropathic itch. In: Carstens E, Akiyama T, editors. Itch: Mechanisms and Treatment. Boca Raton, FL: CRC Press/Taylor and Francis Group, LLC (2014), 89-118.

5. Pereira MP, Derichs L, Meyer Zu Horste G, Agelopoulos K. Generalized chronic itch induced by small-fibre neuropathy: clinical profile and proposed diagnostic criteria. J Eur Acad Dermatol Venereol. (2019) 34:1795-802. doi: $10.1111 /$ jdv.16151

6. Misery L, Bodere C, Genestet S, Zagnoli F, Marcorelles P. Small-fibre neuropathies and skin: news and perspectives for dermatologists. Eur J Dermatol. (2014) 24:147-53. doi: 10.1684/ejd.2013. 2189

7. Lee SS, Yosipovitch G, Chan YH, Goh CL. Pruritus, pain, and small nerve fiber function in keloids: a controlled study. J Am Acad Dermatol. (2004) 51:1002-6. doi: 10.1016/j.jaad.2004.07.054

8. Chung BY, Kim HB, Jung MJ, Kang SY. Post-burn pruritus. Int J Mol Sci. (2020) 21:3880. doi: 10.3390/ijms21113880

9. Lee HJ, Kim GW, Kim WJ, Mun JH, Song M, Kim HS, et al. Clinical characteristics of postherpetic pruritus: assessment using a questionnaire, von Frey filaments and Neurometer. Br J Dermatol. (2015) 172:1672-3. doi: 10.1111/bjd.13569

10. Marziniak M, Phan NQ, Raap U, Siepmann D, Schurmeyer-Horst F, PogatzkiZahn E, et al. Brachioradial pruritus as a result of cervical spine pathology: the results of a magnetic resonance tomography study. J Am Acad Dermatol. (2011) 65:756-62. doi: 10.1016/j.jaad.2010.07.036

11. Huesmann T, Cunha PR, Osada N, Huesmann M, Zanelato TP, Phan NQ, et al. Notalgia paraesthetica: a descriptive two-cohort study of 65 patients from Brazil and Germany. Acta Derm Venereol. (2012) 92:535-40. doi: 10.2340/00015555-1344

12. Shumway NK, Cole E, Fernandez KH. Neurocutaneous disease: neurocutaneous dysesthesias. J Am Acad Dermatol. (2016) 74:215-28. doi: 10.1016/j.jaad.2015.04.059

13. Massey EW. Sensory mononeuropathies. Semin Neurol. (1998) 18:177-83. doi: 10.1055/s-2008-1040871

14. Sadeghi P, Papay FA, Vidimos AT. Trigeminal trophic syndrome-report of four cases and review of the literature. Dermatol Surg. (2004) 30:807-12. doi: 10.1111/j.1524-4725.2004.30220.x

15. Magilner D. Localized cervical pruritus as the presenting symptom of a spinal cord tumor. Pediatr Emerg Care. (2006) 22:746-7. doi: 10.1097/01.pec.0000238735.14532.2e

16. Waseem M, Raja A, Jeun E, Prokhorov S, Dobrenkov K. Paroxysmal neuropathic pain in an adolescent female with syringomyelia: a review of literature. Pediatr Emerg Care. (2012) 28:472-4. doi: 10.1097/PEC.0b013e318253907f

17. Ganguly S, Krishna CV, Parmar NV, Kuruvila S, Phansalkar DS. Unilateral pruritus following stroke. Indian J Dermatol Venereol Leprol. (2015) 81:186-8. doi: 10.4103/0378-6323.152294

18. Massey EW. Unilateral neurogenic pruritus following stroke. Stroke. (1984) 15:901-3. doi: 10.1161/01.STR.15.5.901

19. Yamamoto M, Yabuki S, Hayabara T, Otsuki S. Paroxysmal itching in multiple sclerosis: a report of three cases. J Neurol Neurosurg Psychiatry. (1981) 44:1922. doi: 10.1136/jnnp.44.1.19

20. Xiao L, Qiu W, Lu Z, Li R, Hu X. Intractable pruritus in neuromyelitis optica. Neurol Sci. (2016) 37:949-54. doi: 10.1007/s10072-016-2523-Z

21. Pereira MP, Kremer AE, Mettang T, Ständer S. Chronic pruritus in the absence of skin disease: pathophysiology, diagnosis and treatment. Am J Clin Dermatol. (2016) 17:337-48. doi: 10.1007/s40257-016-0198-0

22. Kwatra SG, Ständer S, Bernhard JD, Weisshaar E, Yosipovitch G. Brachioradial pruritus: a trigger for generalization of itch. J Am Acad Dermatol. (2013) 68:870-3. doi: 10.1016/j.jaad.2012.11.026

23. Misery L. Pruritus in cutaneous T-cell lymphomas. In: Carstens E, Akiyama T, editors. Itch: Mechanisms and Treatment. Boca Raton, FL: CRC Press/Taylor and Francis Group, LLC (2014), 119-28.

24. Weisshaar E, Szepietowski JC, Dalgard FJ, Garcovich S, Gieler U, GimenezArnau AM, et al. European S2k guideline on chronic pruritus. Acta Derm Venereol. (2019) 99:469-506. doi: 10.2340/00015555-3164

25. Ständer S, Zeidler C, Augustin M, Bayer G, Kremer AE, Legat FJ, et al. S2k-Leitlinie zur diagnostik und therapie des chronischen pruritus - update - kurzversion. J Dtsch Dermatol Ges. (2017) 15:860-73. doi: $10.1111 /$ ddg.13304_g

26. Steinhoff M, Schmelz M, Szabo IL, Oaklander AL. Clinical presentation, management, and pathophysiology of neuropathic itch. Lancet Neurol. (2018) 17:709-20. doi: 10.1016/S1474-4422(18)30217-5

27. Andersen HH, Akiyama T, Nattkemper LA, van Laarhoven A, Elberling J, Yosipovitch G, et al. Alloknesis and hyperknesis-mechanisms, assessment methodology, and clinical implications of itch sensitization. Pain. (2018) 159:1185-97. doi: 10.1097/j.pain.0000000000001220

28. Carstens E, Akiyama T. Central mechanisms of itch. Curr Probl Dermatol. (2016) 50:11-7. doi: 10.1159/000446011

29. VanDenKerkhof EG, Stitt L, Clark AJ, Gordon A, Lynch M, Morley-Forster $\mathrm{PK}$, et al. Sensitivity of the DN4 in screening for neuropathic pain syndromes. Clin J Pain. (2018) 34:30-6. doi: 10.1097/AJP.0000000000000512

30. Freynhagen R, Tolle TR, Gockel U, Baron R. The painDETECT project - far more than a screening tool on neuropathic pain. Curr Med Res Opin. (2016) 32:1033-57. doi: 10.1185/03007995.2016.1157460

31. Poquet N, Lin C. The Brief Pain Inventory (BPI). J Physiother. (2016) 62:52. doi: 10.1016/j.jphys.2015.07.001

32. Bouhassira D, Attal N, Alchaar H, Boureau F, Brochet B, Bruxelle J, et al. Comparison of pain syndromes associated with nervous or somatic lesions and development of a new neuropathic pain diagnostic questionnaire (DN4). Pain. (2005) 114:29-36. doi: 10.1016/j.pain.2004.12.010

33. Huguen J, Brenaut E, Clerc CJ, Poizeau F, Marcorelles P, Quereux G, et al. Comparison of characteristics of neuropathic and non-neuropathic pruritus to develop a tool for the diagnosis of neuropathic pruritus: the NP5. Front Med. (2019) 6:79. doi: 10.3389/fmed.2019.00079

34. Treister R, Lodahl M, Lang M, Tworoger SS, Sawilowsky S, Oaklander AL. Initial development and validation of a patient-reported symptom survey for small-fiber polyneuropathy. J Pain. (2017) 18:556-63. doi: 10.1016/j.jpain.2016.12.014

35. Pereira MP, Luling H, Dieckhofer A, Steinke S, Zeidler C, Agelopoulos K, et al. Application of an $8 \%$ capsaicin patch normalizes epidermal TRPV1 expression but not the decreased intraepidermal nerve fibre density in patients with brachioradial pruritus. J Eur Acad Dermatol Venereol. (2018) 32:1535-41. doi: $10.1111 /$ jdv.14857

36. Lauria G, Hsieh ST, Johansson O, Kennedy WR, Leger JM, Mellgren SI, et al. European Federation of Neurological Societies/Peripheral Nerve Society Guideline on the use of skin biopsy in the diagnosis of small fiber neuropathy. Report of a joint task force of the European Federation of Neurological Societies and the Peripheral Nerve Society. Eur J Neurol. (2010) 17, 90312, e944-9. doi: 10.1111/j.1468-1331.2010.03023.x

37. Lauria G, Bakkers M, Schmitz C, Lombardi R, Penza P, Devigili G, et al. Intraepidermal nerve fiber density at the distal leg: a worldwide normative reference study. J Peripher Nerv Syst. (2010) 15:202-7. doi: 10.1111/j.1529-8027.2010.00271.x

38. Lauria G, Merkies IS, Faber CG. Small fibre neuropathy. Curr Opin Neurol. (2012) 25:542-9. doi: 10.1097/WCO.0b013e32835804c5

39. Pham M, Bäumer T, Bendszus M. Peripheral nerves and plexus: imaging by MR-neurography and high-resolution ultrasound. Curr Opin Neurol. (2014) 27:370-9. doi: 10.1097/WCO.0000000000000111

40. Pereira MP, Luling $\mathrm{H}$, Dieckhofer A, Steinke S, Zeidler C, Ständer S. Brachioradial pruritus and notalgia paraesthetica: a comparative observational study of clinical presentation and morphological pathologies. Acta Derm Venereol. (2017) 98:82-8. doi: 10.2340/00015555-2789

41. Ringkamp M, Schepers RJ, Shimada SG, Johanek LM, Hartke TV, Borzan J, et al. A role for nociceptive, myelinated nerve fibers in itch sensation. $J$ Neurosci. (2011) 31:14841-9. doi: 10.1523/JNEUROSCI.3005-11.2011

42. Schmelz M. Neuronal sensitivity of the skin. Eur J Dermatol. (2011) 21(Suppl. 2):43-7. doi: 10.1684/ejd.2011.1265

43. Rolke R, Baron R, Maier C, Tolle TR, Treede RD, Beyer A, et al. Quantitative sensory testing in the German Research Network on Neuropathic Pain (DFNS): standardized protocol and reference values. Pain. (2006) 123:231-43. doi: 10.1016/j.pain.2006.01.041

44. Maier C, Baron R, Tolle TR, Binder A, Birbaumer N, Birklein F, et al. Quantitative sensory testing in the German Research Network on Neuropathic Pain (DFNS): somatosensory abnormalities in 1236 patients 
with different neuropathic pain syndromes. Pain. (2010) 150:439-50. doi: 10.1016/j.pain.2010.05.002

45. Magerl W, Krumova EK, Baron R, Tolle T, Treede RD, Maier C. Reference data for quantitative sensory testing (QST): refined stratification for age and a novel method for statistical comparison of group data. Pain. (2010) 151:598-605. doi: 10.1016/j.pain.2010.07.026

46. Walk D, Sehgal N, Moeller-Bertram T, Edwards RR, Wasan A, Wallace $M$, et al. Quantitative sensory testing and mapping: a review of nonautomated quantitative methods for examination of the patient with neuropathic pain. Clin J Pain. (2009) 25:632-40. doi: 10.1097/AJP.0b013e318 $1 \mathrm{a} 68 \mathrm{c} 64$

47. Cohen AD, Masalha R, Medvedovsky E, Vardy DA. Brachioradial pruritus: a symptom of neuropathy. J Am Acad Dermatol. (2003) 48:825-8. doi: $10.1067 / \mathrm{mjd} .2003 .494$

48. Cohen AD, Vander T, Medvendovsky E, Biton A, Naimer S, Shalev R, et al. Neuropathic scrotal pruritus: anogenital pruritus is a symptom of lumbosacral radiculopathy. J Am Acad Dermatol. (2005) 52:61-6. doi: 10.1016/j.jaad.2004.04.039

49. Donadio V, Liguori R. Microneurographic recording from unmyelinated nerve fibers in neurological disorders: an update. Clin Neurophysiol. (2015) 126:437-45. doi: 10.1016/j.clinph.2014. 10.009

50. Merkies IS, Faber CG, Lauria G. Advances in diagnostics and outcome measures in peripheral neuropathies. Neurosci Lett. (2015) 596:3-13. doi: 10.1016/j.neulet.2015.02.038

51. Yosipovitch G, Goon AT, Wee J, Chan YH, Zucker I, Goh CL. Itch characteristics in Chinese patients with atopic dermatitis using a new questionnaire for the assessment of pruritus. Int J Dermatol. (2002) 41:212-6. doi: 10.1046/j.1365-4362.2002.01460.x

52. O'Neill JL, Chan YH, Rapp SR, Yosipovitch G. Differences in itch characteristics between psoriasis and atopic dermatitis patients: results of a web-based questionnaire. Acta Derm Venereol. (2011) 91:537-40. doi: 10.2340/00015555-1126
53. Pogatzki-Zahn EM, Pereira MP, Cremer A, Zeidler C, Dreyer T, Riepe $\mathrm{C}$, et al. Peripheral sensitization and loss of descending inhibition is a hallmark of chronic pruritus. J Invest Dermatol. (2020) 140:203-11.e204. doi: $10.1016 /$ j.jid.2019.05.029

54. Maddison B, Parsons A, Sangueza O, Sheehan DJ, Yosipovitch G. Retrospective study of intraepidermal nerve fiber distribution in biopsies of patients with nummular eczema. Am J Dermatopathol. (2011) 33:621-3. doi: 10.1097/DAD.0b013e3181fe4c3c

55. Hashimoto T, Kursewicz CD, Fayne RA, Nanda S, Shah SM, Nattkemper L, et al. Pathophysiologic mechanisms of itch in bullous pemphigoid. J Am Acad Dermatol. (2019) 83:53-62. doi: 10.1016/j.jaad.2019.07.060

56. Milian-Ciesielska K, Chmura L, Dyduch G, Jagers C, Radwanska E, Adamek D. Intraepidermal nerve fiber density in vulvar lichen sclerosus and normal vulvar tissues. J Physiol Pharmacol. (2017) 68:453-8.

57. Brewer KL, Lee JW, Downs H, Oaklander AL, Yezierski RP. Dermatomal scratching after intramedullary quisqualate injection: correlation with cutaneous denervation. J Pain. (2008) 9:999-1005. doi: 10.1016/j.jpain.2008.05.010

58. Zhong W, Yang M, Zhang W, Visocchi M, Chen X, Liao C. Improved neural microcirculation and regeneration after peripheral nerve decompression in DPN rats. Neurol Res. (2017) 39:285-91. doi: 10.1080/01616412.2017.1297557

Conflict of Interest: The authors declare that the research was conducted in the absence of any commercial or financial relationships that could be construed as a potential conflict of interest.

Copyright $\odot 2021$ Pereira, Wiegmann, Agelopoulos and Ständer. This is an openaccess article distributed under the terms of the Creative Commons Attribution License (CC BY). The use, distribution or reproduction in other forums is permitted, provided the original author $(s)$ and the copyright owner(s) are credited and that the original publication in this journal is cited, in accordance with accepted academic practice. No use, distribution or reproduction is permitted which does not comply with these terms. 